MUZIKOLOŠKI ZBORNIK - MUSICOLOGICAL ANNUAL VIII, LJUBLJANA 1972

\title{
PARTHIA IN TRIJE CONCERTI JOHANNA ADAMA SCHEIBLA V ARHIVU ŠTUDIJSKE KNJIŽNICE V PTUJU
}

Andrej Rijave c (Ljubljana)

$\mathrm{V}$ novejšem slovenskem glasbenem zgodovinopisju se je ime skladatelja Johanna Adama Scheibla pojavilo prvič leta 1967, v katalogu »Glasbeni rokopisi in tiski na Slovenskem do leta 1800 «, in sicer $\mathrm{v}$ zvezi $\mathrm{z}$ gradivom, ki ga na eni strani hrani novomeški frančiškanski samostan, na drugi pa Študijska knjižnica v Ptuju. Sestavljalca kataloga sta $v$ tej zvezi med drugim opozorila »na dela dveh doslej najbrž malo znanih ustvarjalcev, Johanna Adama Scheibla, ,organiste ad S. Hypolitum', in Johanna Michaela Steinbacha «. ${ }^{1}$ Obenem sta za ptujsko rokopisno zbirko, ki po vsej verjetnosti zares izhaja $\mathrm{z}$ gradov $\mathrm{v}$ okolici Ptuja, čeprav manjkajo za to neposredni dokazi in so zato možne samo domneve o njenem izvoru, ugotovila »slogovno zaokroženost, saj se vsa njena dela gibljejo v okviru srednjeevropskega zgodnjega klasicizma«. že naslednje leto je Walter Graf v svojem članku »Johann Adam Scheibl und die St. Pöltner Stiftsmusik" pri pregledu skladateljevih del in njih nahajališč upošteval tudi slovensko gradivo. ${ }^{2}$ Oba vira sta odmevala $\mathrm{v}$ »Tokovih glasbene kulture na Slovenskem «, ${ }^{3}$ ne da bi se avtor podrobneje pomudil z opusom skladatelja Scheibla, kar ni bil niti njegov namen, saj bi to vprašanje zahtevalo nadaljnjo, področno študijo, ki bi zaokrožitev dane tematike potisnila v nedogled. In vendar se zdi podrobnejša obravnava njegovega skladateljskega opusa, ki in kakor se je ohranil na Slovenskem, zanimiva iz vrste vzrokov, med katerimi je gotovo tudi ta, da bera na Slovenskem ohranjenih kompozicij, še zlasti tistih, ki so nastale na prehodu iz baroka $\mathrm{v}$ klasiko, ni ravno bogata, tako da vsako novo delo vedno znova bistveno dopolnjuje stilno podobo glasbenih prizadevanj nakazanega obdobja. Še prav posebno nam manjka spomenikov posvetne in še posebej instrumentalne glasbene literature, kar nas zopet vrne $\mathrm{k}$ Grafovemu orisu sanktpöltenskega skladatelja, ki je bil predvsem cerkveni skladatelj,

1 Opus cit., sestavila J. Höfler in I. Klemenčič, Ljubljana 1967, 8, 44, 69.

2 Opus cit., Unsere Heimat, Wien XXXIX/1968, 99.

3 Höfler J., Ljubljana 1970, 113. 
tako da njegova ocena sladateljskega dela sloni predvsem na upoštevanju cerkvenih skladb. ${ }^{4}$ Pregled Scheiblovih del pa ravno kaže, da je bil skladatelj tudi plodovit na posvetnem področju, saj samo škofijski arhiv v Gradcu hrani kar trinajst simfonij in dva divertimenta. $\mathrm{Pa}$ še nekaj je zanimivo: $\mathrm{z}$ izjemo ene simfonije, ki jo hranijo v Kremsmünstru, kjer so Scheibla v njegovem času imeli za skladatelja »uporabne cerkvene glasbe $",{ }^{5}$ so vsa do danes znana posvetna dela zbrana v hraniliščih na (avstrijskem in slovenskem) stajerskem in na Kranjskem; ali konkretno: v Gradcu, Ptuju in Novem mestu. Seveda se ob tem odpirajo vprašanja, na katera trenutno ne najdemo odgovora: Zakaj tako? Zakaj ravno na tem področju? Kakšne so bile zveze tega skladatelja s štajersko in Kranjsko? Po kakšnih poteh so dospele vse te posvetne - orkestralne, komorne in solistične - kompozicije $\mathrm{v}$ aristokratske plemiške zbirke oziroma večje cerkvene centre, kjer so čutili potrebo po posvetnem muziciranju. Glede vseh teh in podobnih vprašanj lahko samo bolj ali manj domnevamo: verjetno po isti poti, kakor so prihajale in po avstrijskem prostoru krožile kompozicije takih skladateljev kot so bili Georg Christoph Wagenseil, Florian Leopold Gassmann, Mathias Georg Zechner in drugi, in kakor je to leta 1772 ob svojem dunajskem obisku odlično izrazil Charles Burney: "As there are no music shops in Vienna, the best method of procuring new compositions is to apply to copyists... none is printed « ${ }^{6}$

Predno bi se lotili v naslovu navedenih skladb, kaže osvežiti biografske podatke o Johannu Adamu Scheiblu, ki sodi med najpomembnejše nižjeavstrijske skladatelje terezijanske dobe. ${ }^{7}$ Od začetka štiridesetih let pa do svoje smrti 1773 je deloval kot »organista et compositor" oziroma "chori regens et capellae Hippolitensi magister« pri avguštincih v St. Pöltnu na Nižjem Avstrijskem, ki so v skladu z naziranji ustanovitelja reda bili glasbi še posebno naklonjeni, tako da je Scheibl ob ugodni ustvarjalni klimi lahko našel široko področje poustvarjalnega in ustvarjalnega delovanja. Pri tem je treba poudariti tesne stike, ki so jih imeli nižjeavstrijski prelati $\mathrm{z}$ dvorom, kar je našlo svoj odmev tudi v stikih dvornih umetnikov z ustreznimi cerkvenimi in samostanskimi ustanovami. To in ono in ne nazadnje sorodstvene zveze $\mathrm{z}$ dvornimi umetniškimi krogi so Johannu Adamu Scheiblu omogočile, da je bil na tekočem, kar se je na glasbenem področju odvijalo na cesarskem Dunaju.

Že takoj na začetku pa je treba opozoriti, da je v svetovni glasbeni zgodovini v okviru "predklasične dunajske šole« njen najbolj pomembni predstavnik Wagenseil označen kot »Kleinmeister«, torej

${ }^{4}$ Prim. Schenk E., Instrumentale Kirchenmusik, Bericht 2. Internationalen Kongresses für Katholische Kirchenmusik, Wien 1955, 174 sl. 5 Kellner A., Musikgeschichte des Stiftes Kremsmünster, Kassel \& Basel, 1956, 380.

${ }^{6}$ Dr.Burney's Musical Tours in Europe. Ed. P.A.Scholes, London 1959 , II, $121 \& 124$.

$7 \mathrm{Ti}$ in nadaljnji podatki so posneti po Grafu, ib. 
kot skladatelj, ki sicer sledi kompozicijskim pravilom, a mu manjka originalnosti, ki je bistvena značilnost vsakega umetniškega dela. ${ }^{8}$ Kakšno »uvrstitev« je torej šele pričakovati za Johanna Adama Scheibla, čeprav je na drugi strani res, da so že omenjeni dunajski in nedunajski "predklasični« skladatelji bili v svojem času malo znani ravno zategadelj, ker so raje ostajali bolj doma in ker je tudi njihova glasba ostajala - in še vedno ostaja - največkrat v rokopisu. $\mathrm{K}$ razkrivanju in boljšemu poznavanju dela enega izmed takih "malih" mojstrov naj torej prispeva tale sestavek.

Študijska knjižnica v Ptuju hrani štiri Scheiblove kompozicije: "Parthio ex $\mathrm{C}$ «, »Concerto ex $\mathrm{C}$ «, »Concerto ex $\mathrm{F}$ « in »Concerto ex G«. Ohranjeni so samo parti v kvartnem formatu, tako da je za analizo bilo treba vse štiri obsežne kompozicije spartirati. Glede na napake, pomanjkljivosti in manjkajoče dele, kaže, da gre pri partih za prepise. Kje je originalna partitura, če je sploh še ohranjena, je seveda drugo vprašanje. Iz Grafovega pregleda je razvidno, da gre za doslej edine znane zapise omenjenih skladb, kar ptujskim manuskriptom zvišuje vrednost ter stopnjo zanimivosti. V originalu beremo: Parthia Ex C / Di Cembalo / Violino Primo / Violino Secondo / Basso, Concerto Ex C / à / Clavi Cembalo / Violino Primo / Violino Secondo / Clarino Primo - Clarino Secondo (ad lib.) / e / Basso, Concerto Ex F / à / Clavi Cembalo / Violino Primo / Violino Secondo / e / Basso ter Concerto Ex G / Di Cembalo / Con / Violino Primo / Violino Secondo / Basso. Povsod je bolj ali manj popolno označen avtor, medtem ko prepisovalec ni naveden. Prav tako ni nikjer datuma nastanka posameznih kompozicij oziroma prepisov, kaj šele označbe opusa, kar onemogoča "zunanjo« razvrstitev. Razvrstitev po kakršnihkoli "notranjih" kriterijih se zdi tvegana, saj pripadajo značilnosti posameznih elementov kompozicijskega stavka $\mathrm{v}$ teh štirih skladbah istemu kompozicijskemu hotenju, in sicer hotenju, ki je že doseglo določeno izoblikovano stopnjo, v okviru katere ni smiselno iskati nekakšen kompozicijsko-tehnični in stilni "razvoj«; se pravi, da imamo kljub določenim posebnostim, ki prihajajo na površje zdaj $\mathrm{v}$ tej zdaj $\mathrm{v}$ oni kompoziciji, opraviti s formiranimi kompozicijskimi prijemi, ali z drugimi besedami: posamezne kompozicije so samo variantne rešitve istega kompozicijskega mišljenja.

Kot je razvidno iz pravkar naštetih naslovov, imajo vse štiri skladbe - z izjemo Concerta ex $\mathrm{C}$, ki dopušča možnost soigre dveh klarinetov - isto zasedbo: prva violina, druga violina, čembalo ter »basso«, ki največkrat podvaja basovski part prejšnjega instrumenta. V osnovi imamo torej opraviti s tipično »trio« zasedbo: dve solistični liniji plus instrument s tipkami, ki ponekod zares igra continuo. Godalni basovski part je v Parthii, razen v naslovu, označen $\mathrm{z}$ »Violonzello«, v Concertih pa z »Basso", kar ni nič nenavadnega, saj je še v Haydnovih kvartetih najnižji part tretiran kot »Basso«. Omenjeni glas ne gre nikoli pod zvočni domet violončela, vendar je

8 Newmann W., The Sonata in the Classic Era, Chapel Hill 1963, 354. 
imeti za možno tako uporabo tega instrumenta kot tudi kontrabasa ali obeh hkrati. Ni pa viole, ki se je v komorni glasbi pojavila okoli leta $1745^{9}$ in je rezultat simfoniranja tematičnega dela $\mathrm{v}$ vseh štirih glavnih zvočnih registrih. ${ }^{10}$ Te ugotovitve kažejo na dvoje: na možni čas nastanka kompozicij in/ali na stilno orientacijo skladatelja. Vsekakor pa je zasedba, taka kot je, bolj značlna za sredi 18. stoletja izginjajočo estetiko. Predstavlja pa ključno instrumentalno telo, iz katerega so se $\mathrm{v}$ drugi polovici istega stoletja, deloma vzporedno, deloma sukcesivno, razvile najrazličnejše komorne godalne zasedbe $\mathrm{s}$ čembalom oziroma pozneje $s$ klavirjem ali brez njega. ${ }^{11}$ Seveda pa dopuščajo partiture tudi možnost korične zasedbe partov in $s$ tem zvočno polnejše izvedbe.

Zanimivo je, da so citirane kompozicije naslednice dveh osnovnih baročnih cikličnih instrumentalnih tvorb: sonate da camera in sonate da chiesa. Med razvojne različice prve sodi Scheiblova Parthia. Kar zadeva sam naslov - Parthia, Partia, Parthie, Partie oziroma bolj pogosto Partita - je le-ta samo eno izmed možnih imen za suito, ${ }^{12}$ saj so skladbe $\mathrm{z}$ naslovi Parthien pisali že skladatelji, kot so bili Froberger, Kuhnau ali Krieger, medtem ko sta partite med drugimi pisala tako Johann Sebastian Bach kot Scheiblu gotovo bližji dunajski dvorni komponist Johann Joseph Fux. ${ }^{13}$ Značilnost suite, zlasti komorne, je $\mathrm{v}$ njeni variabilnosti. ${ }^{14}$ Glede na odstopanje od tistih stavkov, ki naj bi v tedanji suiti predstavljali bolj ali manj obvezujoče ogrodje, kakor tudi glede na njih precejšnje število, bi Scheiblovo Parthio lahko dopolnili $\mathrm{z}$ »alla francese«, kot so skladatelji sami $\mathrm{v}$ tistem času označevali take kompozicije. ${ }^{15}$ Francoske vplive lahko iščemo tudi $\mathrm{v}$ uvajanju dveh menuetov $\mathrm{s}$ triom pa še ario po vrhu, kot je to - v variantah - delal Johann Sebastian Bach v svojih »Francoskih suitah«, italijanske zopet v stavkih, kot so "Introduzione" ali "Capriccio«, ki imajo svoj izvor v kompozicijski praksi italijanskih skladateljev poznega 17 . stoletja. ${ }^{16} \mathrm{~S}$ tem pa imamo že vse stavke Scheiblove suitne kompozicije: Introduzione, Capriccio, Menuet \& Trio, Aria, Menuet \& Trio, Finale.

Skladba je napisana v C-duru, razen obeh trijev in arije, ki so v a-molu, kar je zopet tipično za takratno hotenje po zvočnem kontrastu, ki so ga $\mathrm{v}$ teh in takih primerih skoraj maniristično dosegali $\mathrm{z}$ izmenjavo med paralelnimi ali istoimenskimi durovskimi in molovskimi tonalitetami. Pri tem je, kot je splošno znano, bil a-mol skupaj

${ }^{9}$ Ulrich H., Chamber Music, 2. ed., New York \& London, 1966, 125.

${ }^{10} \mathrm{~V}$ tem se že omenjeni Johann Michael Steinbach kaže naprednejši, saj v vseh podobnih kompozicijah uporablja že violo.

11 Prim. Ulrichovo pregledno tabelo, ib., 128. 1970, 645

12 Apel.W., Harvard Dictionary of Music, 2. ed., Cambridge Mass.,

13 Liess A., Johann Joseph Fux, Wien 1948, 51; Newmann W., The Sonata in the Baroque Era, Chapel Hill 1966, 255 sl.

${ }_{14}$ Beck H., The Suite, Köln 1966, 29.\& 38.

15 MGG XII, 1720; Beck H., ib., 31-32.

16 Beck H., ib., 30. 
z nekaterimi drugimi molovskimi tonalitetami še prav posebno prikladen za »žalostne efekte «. ${ }^{17}$ Harmonski jezik je v Parthii sploh preprost; lahko bi dejali: "šolsko« pravilen, saj sestoji predvsem iz kvintakordov in njih obrnitev ter občasnih (dominantnih) septakordov - $\mathrm{z}$ ustreznim podvajanjem osnovnih tonov oziroma zapovrstjem njihovega izpuščanja, čeprav ne manjka mest, kjer odsotnost terce povzroča "prazen « zvok; modulira s pomočjo skupnih stopenj, medtem ko so kromatične modulacije enostavne. In vendar je tak harmonski stavek značilen za »predklasične« kompozicije, iz katerih izginja »spletajoča se« (Fortspinnung) melodika, polifonska sprepletenost glasov ter $\mathrm{s}$ tem $\mathrm{v}$ zvezi hitro se menjajoča harmonska faktura. Namesto tega - tudi pri Scheiblu, in v tej skladbi - postajajo, v kolikor že niso postale, glasbene misli v sebi zaokrožene, harmonsko podprte in kadenčno urejene, kar ima na oblikovni ravni za posledico vse večjo periodično strukturiranost; v plesnih stavkih še toliko bolj.

Kjer ni polifonije, se zmanjša pomen kontrapunkta, saj ni nasprotnih, kontrastnih misli. Vsak stavek je v sebi »baročno m monotematičen, pri čemer Scheibl ne stremi za kako višjo enovitostjo, ki bi stavke po glasbenem materialu med seboj povezovala. ${ }^{18} \mathrm{Kljub}$ temu pa lahko v vsakem izmed stavkov odkrijemo tri vrste glasbenega gradiva (od bolj $\mathrm{k}$ manj pomembnemu): tematično, sekvenčno in prehodno, ki pa je tako melodično kot ritmično izpeljivo iz prejšnjih dveh. Tematično je največkrat simetrično in periodično urejeno, ne da bi bile ponovitve vedno enako izčrpne ali sploh doslovne. Sekvence se pojavljajo tudi $\mathrm{v}$ okviru tematičnega. Ob odsotnosti kontrastne tematike dosega namreč skladatelj večjo raznovrstnost glasbenega toka tudi s sekvenčnim projiciranjem tematičnega skozi različne tonalitete. V kolikor ne gre za ponovitve, so te projekcije vedno variante izhodiščne glasbene misli. Odondod tekoča nedramatičnost in nekonfliktnost Scheiblovega glasbenega izražanja v Parthii. Preproščino podpira tudi prozornost in lahkotnost fakture, $\mathrm{v}$ kateri se vodilna linija - skoraj izključno v I. violini oziroma v diskantu čembala - drži večinoma harmonskih tonov, tako da so harmonsko tuji toni menjalnega ali prehajalnega značaja. Ostali parti samo dopolnjujejo glavno linijo, radi nastopajo v vzporednih tercah, sekstah in decimah ter s tem samo stopnjujejo svojo harmonsko fundiranost in nesamostojnost. Vse to seveda prispeva $\mathrm{k}$ neproblematičnosti zvoka, ki bi ob večji skladateljevi invenciji lahko bil tudi umetniško opravičen. Tako pa sledi skladba diletantskim potrebam dobe; ${ }^{19}$ ali bolj pozitivno, kar velja bolj ali manj za vsa obravnavana dela: marsikaj "galantnega" je v njih, kar pa se ne kaže toliko v enovitosti tematike in motivike, kolikor $\mathrm{v}$ enotnosti stila in manire. Skladatelju gre za lahkoten "konverzacijski ton«, v okviru katerega bi vsakršen bolj

17 Dorian F., The History of Music in Performance, New York 1942, 142.

18 Beck H., ib., 59.

${ }^{19}$ Ulrich H., ib., 114-115. 
»učen« odnos do glasbene materije mejil na pedanterijo, izkazoval bi pravzaprav pomanjkanje okusa in občutka za pravo mero. ${ }^{20}$

Formalno kot tudi kompozicijsko-tehnično, to je glede vsega tistega, kar sodi v métier, skoraj ni imeti pripomb. Pač pa kaže omeniti skladateljeve oblikovne rešitve, kakor se kažejo v posameznih stavkih. Najbolj svoboden je rondojski Introduzione, medtem ko v trikratnem nastopu tematičnega izkazuje Capriccio prejšnjemu podobno, a bolj strnjeno obliko A A A. V vseh ostalih stavkih, plesnih in neplesnih, uporabi Scheibl bolj ali manj enostavne različice forme, ki jo razvije v obeh menuetih. Za primer naj bo drugi menuet:

\begin{tabular}{lllr}
\multicolumn{4}{c}{ I. del } \\
(16-taktna & perioda) \\
a & b & a & $b_{1}$ \\
T & D & T & T
\end{tabular}

II. del

$\begin{array}{cccccccc}\mathrm{a} & \mathrm{b} & \mathrm{a} & \mathrm{b}_{1} & \mathrm{a}_{1} & \mathrm{a}_{1} & \mathrm{~b}_{1} & \mathrm{~b}_{1} \\ \mathrm{~T} & \mathrm{D} & \mathrm{T} & \mathrm{T} & \mathrm{D} & \mathrm{T} & \mathrm{T} & \mathrm{T}\end{array}$

Oba dela se seveda ponavljata. Opozoriti pa je na dvoje: na povezanost tematičnega $\mathrm{z}$ jasnim kadenčnim sosledjem, kakor tudi na vedno znova pojavljajočo se ponovitev »druge« (b) misli v zaključku, kar utrjuje občutek zaokroženosti, dokončnosti. V Ariji in Finalu ostane Scheibl na tej ravni. V obeh Menuetih pa se $\mathrm{z}$ osrednjimi trii, ki so analogno zgrajeni, povzpne do trodelne da capo forme.

Posebej velja opozoriti na okraševanje, ki je najbolj bogato $\mathrm{v}$ čembalskem partu. Tega vprašanja nikakor ni mogoče preskočiti, saj bi odsotnost zahtevanega okraševanja prizadela strukturo dela, še zlasti, ker okraski bistveno prispevajo $\mathrm{k}$ njegovemu stilu in njegovi izraznosti. Se pravi, da okraski pri Scheiblu ne predstavljajo nekakšnega dodatka, ampak so integralna sestavina glasbenega tkiva. ${ }^{21}$ Tako najdemo $\mathrm{v}$ Parthii, in prav tako $\mathrm{v}$ Concertih, vrsto različnih okraskov, kot so kratki mordent, trilčki, tirata, arpeggio, accaciatura in appogiatura. Izvajati jih je seveda treba $\mathrm{v}$ skladu $\mathrm{z}$ naziranji takratnih teoretikov in $n$ jih sodobno prakso, ki je vedno upoštevala tudi lokalne posebnosti.22

V Parthii so vsi parti izpisani, ne pa tudi v Concertih, kar kaže na starejšo, v tistem času že odmirajočo prakso. V vseh treh Concertih sloni ponekod čembalski delež na izčrpno označenem generalbasu, ki pa se je že odmaknil od baročne prakse. Še leta 1708 je Johann Gottfried Walther v svojem spisu »Praecepta der Musicalischen Composition « med drugim namreč zapisal: "Basso continuo... gehet vom Anfange eines musicalischen Stückes biss zu dessen Ende ohne vicles und langes pausiren continuirlich fort, ... und hält alle andere

20 Dahlhaus C., Analyse und Werturteil, Mainz 1970, 56.

21 Dorian F., ib., 89.

22 Prim. Dorian F., ib., 87 sl.; Dolmetsch A., The Interpretation of Music of the XVII and XVIII Centuries, London 1946, 88 sl.; Donington R., The Interpretation of Early Music, London 1963, 117 sl. 
Stimmen vollkömmlich in sich «. ${ }^{23}$ To v Scheiblovem primeru ne drži več, saj je basso continuo le redko uporabljen, čeprav vedno na istih oziroma podobnih mestih, in sicer povsod tam, kjer čembalo sekundira glavnim glasbenim mislim (pa tudi iz njih izpeljanih delov), ko se le-te pojavljajo $\mathrm{v}$ godalih.

Kar zadeva sam naslov - Concerto, je tu odlično pričanje istega znamenitega teoretika. Zanimivo je, da njegova razlaga te oblike $\mathrm{v}$ glavnem ustreza tistemu, kar kažejo Scheiblovi Concerti. V njegovem glasbenem leksikonu iz leta 1732 beremo po uvodni razlagi francoske besede »Concert " kot glasbene prireditve tudi tole: »2) Eine sowohl Vocal- als Instrumental-Cammer-Music, (d.i. ein Stück, das Concerto heist), und 3) Violin-Sachen, die also gesetzt sind, dass eine jede Partie sich zu gewisser Zeit hervor thut, auch mit den andern in die Wette spielet. Derowegen denn auch in solchen Sachen, worinn nur die erste Partie dominiert, ... ${ }^{24}$

Concerto ex C ima tri stavke: Allegro, Larghetto, Allegro. Prav toliko stavkov imata tudi Concerto ex F - Tempo giusto, Andante affettuoso, Allegro, ter Concerto ex G - Tempo giusto, Adagio, Allegro-Finale. Že ta trostavčnost kaže na italijanske vplive, naj so le ti imeli svoje izhodišče bodi $\mathrm{v}$ beneški bodi $\mathrm{v}$ napolitanski šoli. Odkloni od te sheme pomenijo $v$ okviru teh šol izjemo, ${ }^{25}$ pa čeprav se $v$ evropski glasbi srede 18. stoletja najdejo najrazličnejše rešitve. Slednje odsevajo tako stilno usmerjenost ustvarjalca kakor prenekaterikrat tudi okus naročnika. ${ }^{26}$ Oboje kaže pri Scheiblu na usmerjenost zgledovanja po instrumentalnem razvoju južno od Alp. To dokazuje tudi kompozicijski stavek, ki je v svojem bistvu "à tre«, stavek, ki je že od leta $1650 \mathrm{v}$ Italiji dominiral tudi v operi, medtem ko se je instrumentalna glasba na severu trdovratneje oklepala štiri- oziroma petglasnosti. ${ }^{27}$ Od Scheiblovih treh Concertov predstavlja Concerto ex $\mathrm{C}$ posebnost. Po želji lahko $\mathrm{v}$ obeh mejnih stavkih sodelujeta dva klarina (in $\mathrm{C}$ ); $\mathrm{v}$ tematičnih delih in $\mathrm{v}$ pasusih, ki so letem po fakturi sorodni, ter $\mathrm{v}$ zaključnih taktih "fanfarno poudarjajo dominantne in tonične harmonije. Ker so »ad libitum«, lahko odpadejo, s čimer se zasedba skrči na čembalo in godala. Ker pa I. in II. violina igrata "unisono", je izvajalcem v vsej tej variabilnosti dana možnost, da tretirajo partituro kot duo za violino in čembalo, kar dopušča obravnavo te kompozicije v okviru tistih oblik, ki so deloma pogojevale deloma pa spremljale nastanek sonate-za violino in klavir. Pa še nekaj: če ne gre za neposredne francoske (lullyjevske) vplive,

23 Jenaer Beiträge zur Musikforschung, Bd. 2, hrsg. v. P. Benary, Leipzig $1955,41$.

24 Walther J.G., Musikalisches Lexikon, Leipzig 1732, 179. Documenta Musicologica, Erste Reihe. III. Hrsg. v. R. Schaal, Kassel \& Basel 1953.

${ }_{25}$ Prim. Schenk E., The Italian Trio Sonata, Cologne 1955, 12; Hutchings A., The Baroque Concerto, London 1961, 135.

${ }^{26}$ Schenk E., Die ausseritalienische Triosonate, Köln 1970, 18.

27 Schenk E., ib., 5. 
je unisono I. in II. violine tudi moral priti po italijanskem (napolitanskem) posredovanju. ${ }^{28}$

Faktura je v vseh treh Concertih v primerjavi s Parthio polnejša, zahtevnejša in vsekakor dospelejša. Po svojem galantno homofonskem tkivu težijo vse tri kompozicije naprej, tako da še navidezne polifonije ni, medtem ko je imitacija med glasovi izjemna. Diskantne linije se največkrat poigravajo $\mathrm{z}$ harmonskimi toni, medtem ko II. violina - podobno tudi drugi »glas « v čembalu - spremlja vodilno linijo najraje $\mathrm{v}$ tercah ali sektah. Sedaj ni več enakopraven in svoboden partner v dialogu: vodstvo je prevzela I. violina, kot to kažejo na primer tudi Tartinijevi trii sredi stoletja. ${ }^{29}$

Melodika - zdaj intervalno in ritmično izrazita, zdaj spevna, zdaj motorično drobeča - je $\mathrm{v}$ Concertih periodizirajoča. Se celo tam, kjer bi kazalo, da gre za "Fortspinnung«, razbije Scheibl dvome $\mathrm{s}$ ponavljanjem motivov, s simetrijo ali s sekvenco. Tudi to kaže na sodobnejšo usmerjenost njegovih partitur. ${ }^{30}$ Zato nastopa (mono) tematični material vedno $\mathrm{v}$ bolj ali manj strogih periodah, $\mathrm{v}$ katerih je opazna tendenca za razširitvijo drugega dela. Tako godala kot čembalo nastopajo $\mathrm{z}$ istim ali morda variiranim tematičnim gradi-
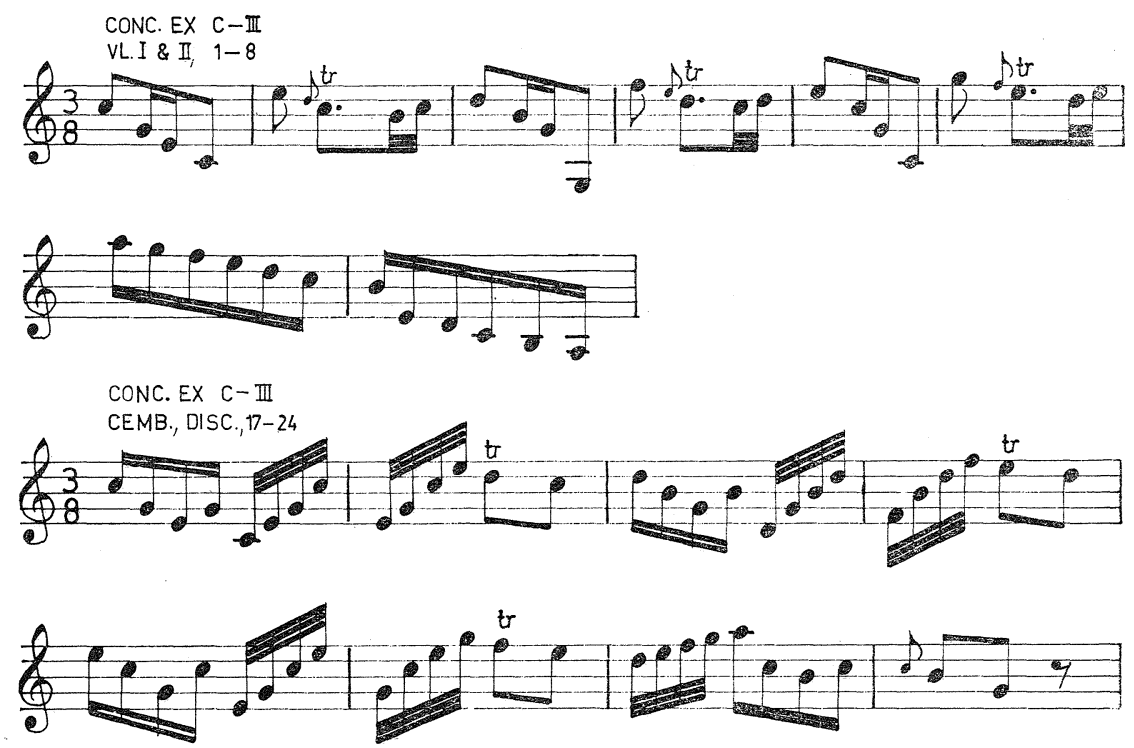

vom, s tem da so čembalski nastopi navadno krajši. Samo v zaključnem Allegru Concerta ex F je vstopne godalne partije imeti za predhodnico čembalovega nastopa, ki je trdnejši, jasnejši in harmonsko prepričljivejši. V nadaljnih nastopih se namreč celovitost začetne godalne periode razblini, čembalove pa ne.

${ }^{28}$ Schenk E., ib., 5; isti, The Italian Trio Sonata, Cologne 1955, 9.

29 Schenk E., ib., 12.

${ }^{30}$ Hutchings A., ib. 
Posebno zanimivo se zdi vprašanje tematičnega v I. stavku Concerta ex F. Izhodiščna, v drugem delu tipično razširjena triindvajsettaktna perioda vsebuje poleg gibanja v četrtinkah, osminkah in
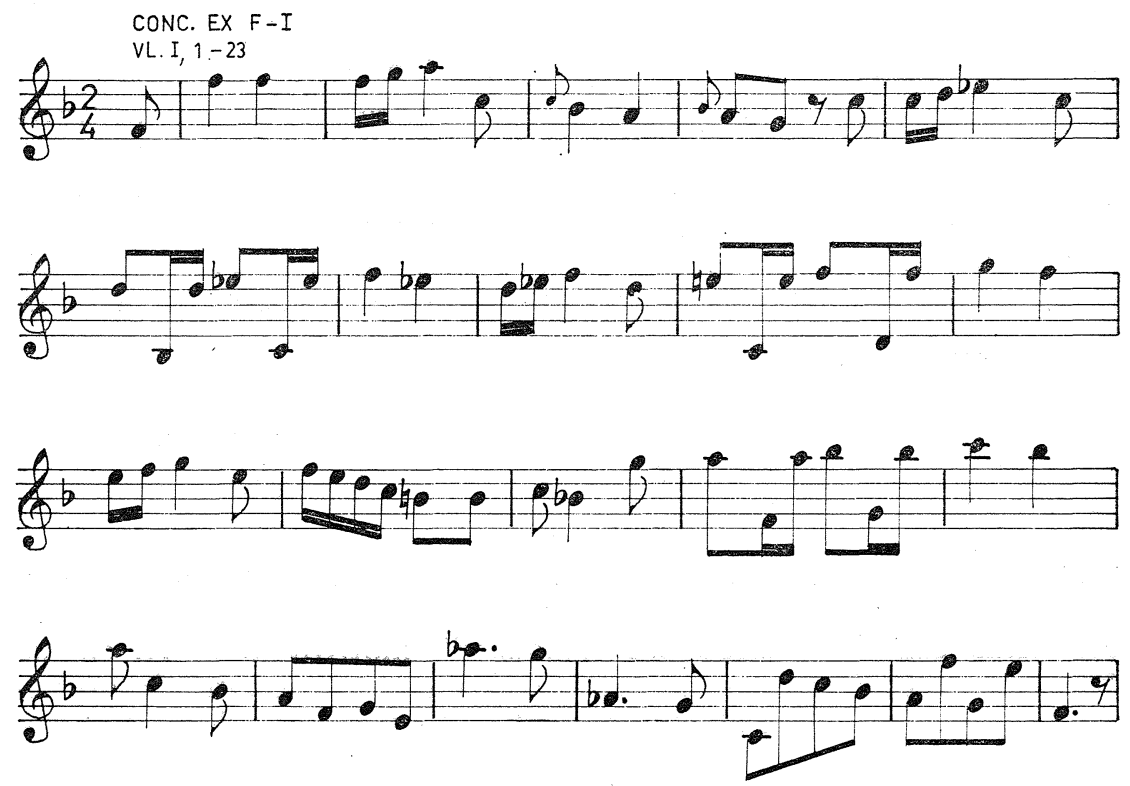

šestnajstinkah dve značilni motivično-ritmični postavki tematičnega gradiva: $\rho_{\rho} \rho$ oziroma $\rho \bullet \&$ posebno v obliki šestnajstinskega dviga na terco in $\mathrm{z}$ večjim intervalnim skokom navzdol, ter zlasti v ritmiziranih sekstah in decimah, ki si sledijo v dvigajočih se sekundah. To in tako gradivo uporablja tudi čembalo, vendar se $\mathrm{v}$

CONC. EX F-I

CEMB., DISC., 105-116
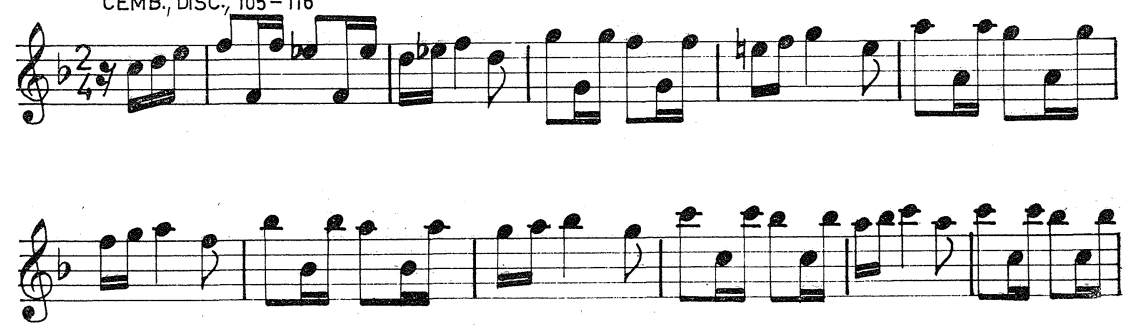

bistvu razlikuje od godal s svojo, s sinkopami redkeje prekinjano motoričnostjo. Že ob prvem nastopu je tako. To seveda ugodno vpliva

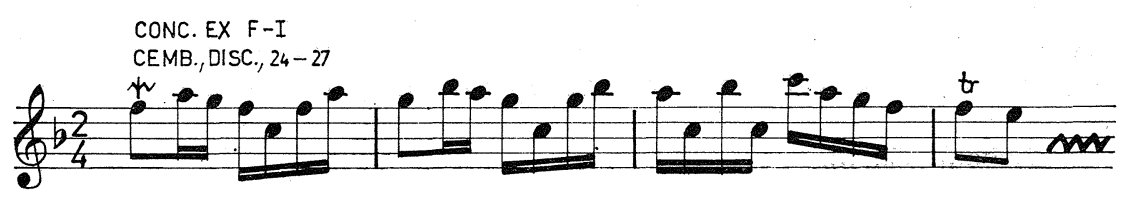

5 Muzikološki zbornik 
na diferenciranost fakture. Ker pa ta glasbena misel prihaja vedno znova na površje po oziroma pred ponovnim nastopom tematičnega, stopa $\mathrm{v}$ ospredje in bi jo zato mogli imeti za čembalov prispevek $\mathrm{k}$ bistvenim glasbenim idejam tega stavka. V sebi ni »kontratematično" izoblikovana, vendar se $\mathrm{v}$ teh in takih »spremljevalnih" tematičnih pasusih lahko iščejo tudi zarodki bitematičnosti.

Začetki še dveh značilnih elementov kompozicijskega oblikovanja, ki jih je krepko razvila dunajska klasika, so prisotni $\mathrm{v}$ teh Scheiblovih skladbah. Najprej je zaslediti ponekod motivično oziroma tematično sorodnost med stavki. Tako na primer med obema Allegroma Concerta ex C. (Prim. tudi prvi notni primer). V obeh je na začetku poudarek na sosledju tonika-dominanta-tonika. Oba-

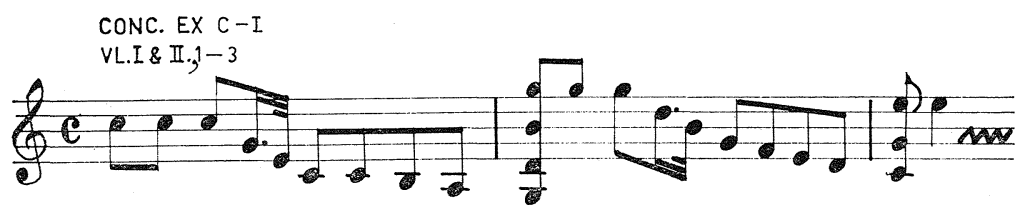

krat imajo godala podobne, ritmično izrazite, padajoče postope. Obakrat se drugi nastop tonične harmonije začne na terci. Ali, veliko bolj transformirana sorodnost izhodiščnih motivov I. in II. stavka Concerta ex G. Mar ni upravičeno iskati skupno "pramisel« ob pogledu na začetke obeh stavkov? V istem Concertu najdemo tudi za-
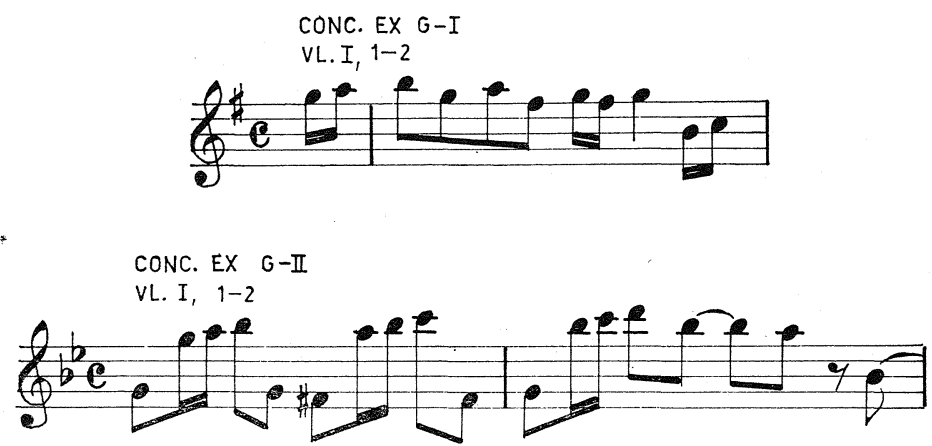

rodke tistega, kar se pozneje imenuje tematično delo. Kot na primer že Pergolesi v svojih trio-sonatah iz leta 1732, ki napovedujejo vodstvo napolitanske šole $\mathrm{v}$ tej formi, ne razvija celotne teme, ampak samo nekatere njene bolj značilne motive, ${ }^{31}$ tako tudi Scheibl dela mestoma podobno, ko $\mathrm{v}$ začetku stavka linearno zastavljene motive pozneje vertikalno konfrontira.

Poleg manj pomembnih prehodnih delov, za katere velja isto kakor v Parthii, so sekvence v Concertih bolj obsežne in obenem važne sooblikovalke forme. Že v vstopnem Allegru Concerta ex C jih

31 Schenk E., ib. 
CONC. EX C-I

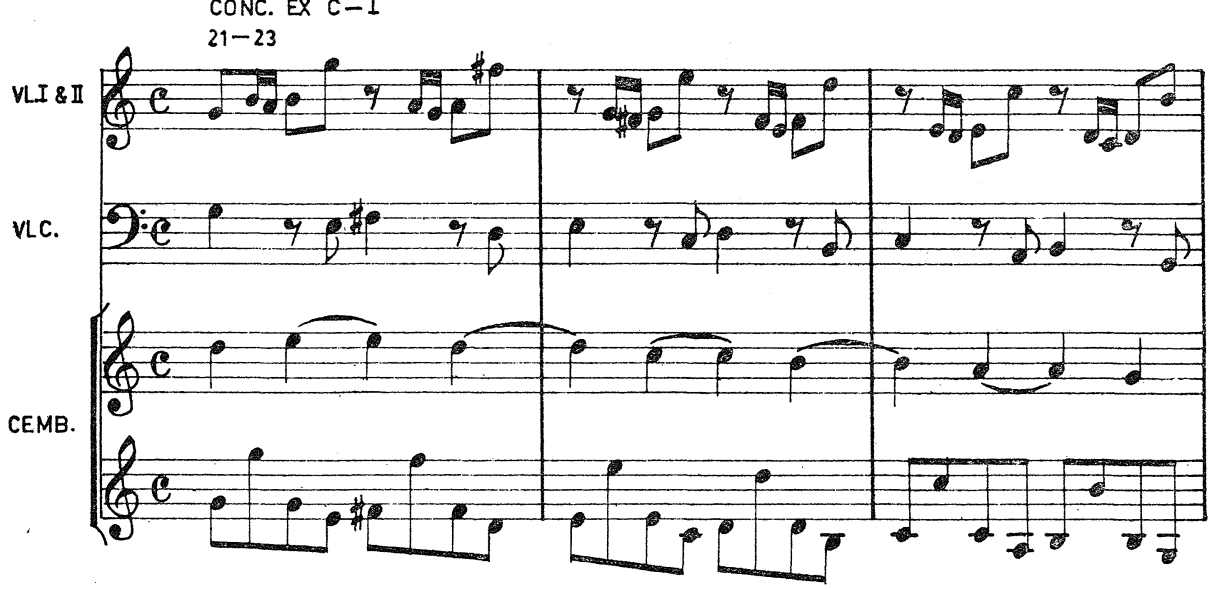

CONC. EX C - I

$43-45$
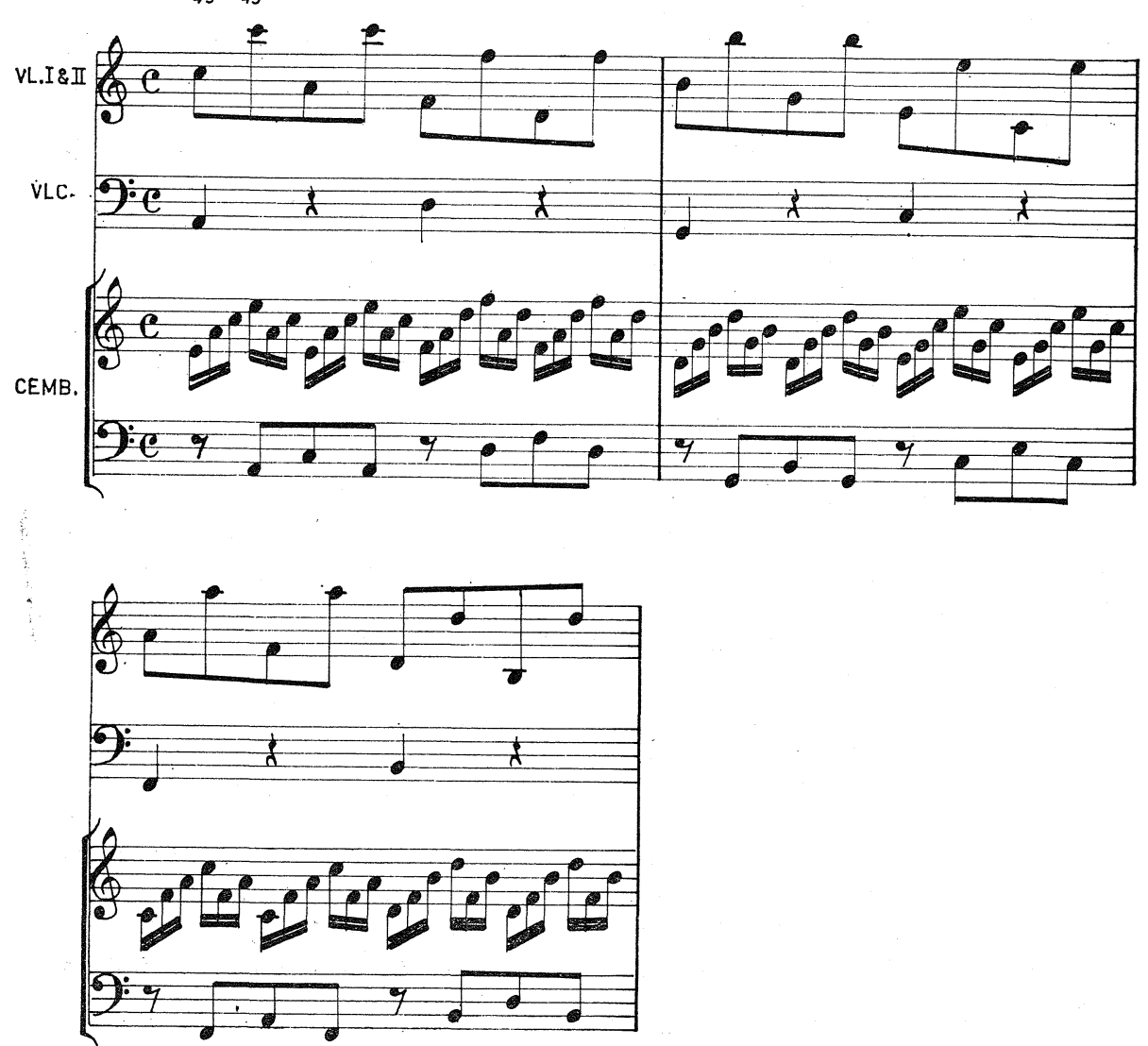
je cela vrsta. Marsikateri današnji poslušalec ima malo potrpljenja za take sekvenčne girlande, ki imajo zelo jasno harmonsko strukturo: III-II, I-VII, VI-V; I-IV, II-V, III-VI; VI-II, V-I, IV-VII in I-IV, VII-III, VI-II, V-I. In vendar so tudi sekvence omogočale nekdanjim izvajalcem spremembo stila ali dinamike in kot nekakšen predah prispevale $\mathrm{k}$ jasnosti in $\mathrm{k}$ večjemu izstopanju tematičnih misli. ${ }^{32}$

$\mathrm{Ne}$ le po fakturi, tudi harmonsko so Concerti bogatejši. Predvsem se je razširila uporaba septakordov, deloma tudi obrnitev, in to ne samo dominantnih, ampak tudi drugih, zmanjšano malih, zmanjšanih in enkrat celo trdo-velikega. Tudi drugod in ne samo kot preje, v sekvencah, zasledimo harmonska sosledja; v Adagiu Concerta ex G v skoraj neprekinjeni septakordni vrsti skozi kvintni krog navzdol od SD do D. Vedno pa je v skladatelju prisotna zavest osrednje tonalitete, od katere se nikoli preveč ne oddalji. To lepo kaže I. stavek Concerta ex F. V vsej množici septakordov »manjka» dominanta subdominante paralele, ki bi uvedla "fis«, česar pa Scheibl ne napravi.

Kar zadeva formo posameznih stavkov, sledi tudi ta italijanskim vplivom. Vsi mejni stavki $\mathrm{v}$ vseh treh Concertih slone na principu ritornellov in ob tri- do štirikratnem bolj ali manj obsežnem nastopu tematičnega gradiva $\mathrm{v}$ godalih in $\mathrm{v}$ čembalu izkazujejo preprosto rondojsko obliko. Pri tem se ritornelli vedno bolj razblinjajo in oddaljujejo od izhodišča, kot na primer v I. stavku Concerta ex G. A ne vedno. V I. stavku Concerta ex F prvi ritornello tudi trdno zaključuje stavek. Vendar: naj so ritornelli tako ali drugače variirani, vedno ostanejo oporni stebri forme. Kot tipičen primer glavnih stavkov naj rabi začetni Allegro Concerta ex C. Če se odmislijo nepomembni prehodni in zaključni takti, nastane naslednja shema:

\section{A sekvenca A sekvenca A sekvenca A sekvenca A}

A vsebuje tako tematično gradivo, ki ga ob bassu continuu čembala prinesejo godala, kot čembalsko ponovitev tematičnega ob skromnejšem deležu godal. Sekvence so med seboj različne, vendar, kar je značilno, so to oddelki, v katerih vsi instrumenti sledijo istemu, ritmično tekočemu toku. Predstavljajo nekakšen "negativen«, ali še bolje, "anti-tutti«.

Ker so zunanji stavki $\mathrm{v}$ duru, so počasni stavki, tako kot pri italijanskih mojstrih prve polovice 18. stoletja, $\mathrm{v}$ molu; in sicer $\mathrm{v}$ istoimenskem, razen $\mathrm{v}$ Concertu ex $\mathrm{F}$, ker je Andante affettuoso v paralelni molovski tonaliteti. Povsod je opaziti stopnjevano in ponekod $\mathrm{v}$ naslovu izraženo čustveno noto ter večjo melodično uglajenost, ki ponekod celo sugerira tekst za kakšno tipično operno situacijo. ${ }^{33}$ Formalne rešitve so različne. Za Larghetto Concerta ex C je značilno izrazno stopnjevanje do dominante, ki ji sledi še krajša

32 Gl. Hutchings A., ib., 145-147.

33 Hutchings A., ib., 135. 
kadenca $\mathrm{v}$ čembalu in ki bi jo Heinrich Schenker gotovo imel za osrednjo, napetostno os stavka. Podobno kot v Menuetih sledi dvakratna zaključna ponovitev drugega dela izhodiščne periode. Andante affettuoso Concerta ex $\mathrm{F}$ ima jasno dvodelno obliko, ki ji ustreza tudi harmonska shema. Ta se lahko zreducira na sosledje: I. del - d-mol, A 7, II 5/3= F-dur VII 5/3, F-dur; II. del - F-dur, A 7, d-mol. Adagio Concerta ex G pa izkazuje podobnosti s Capricciom iz Scheiblove suitne kompozicije, pri čemer je trikratni nastop A-ja kljub harmonskim izmikom vedno $\mathrm{v}$ osnovni tonaliteti.

Tako se nam Johann Adam Scheibl v pravkar prikazanih kompozicijah kaže kot skladatelj, pri katerem prebujajoči se, novi simfonični duh še ni povsem opustil trio-sonatne zasnove, ${ }^{34}$ čeprav kaže, da je v svojih simfonijah, ki odsevajo kvartetno godalno zasnovo in $\mathrm{v}$ katerih nastopajo občasno tudi trobente, rogovi, pozavne in pavke, segel dljè. ${ }^{35} \mathrm{Kljub}$ temu, da glasbena zgodovina na splošno beleži zmanjšanje italijanskega vpliva $\mathrm{v}$ avstrijskih deželah $\mathrm{v}$ njegovem času, ${ }^{36}$ pa je bilo možno ugotoviti številne italijanske vplive $\mathrm{v}$ njegovem kompozicijskem stavku, kar značilno dopolnjuje skladateljsko podobo tega ustvarjalca kakor tudi glasbenega okolja, v katerem je deloval. Vse štiri skladbe - ena suitna in tri koncertne - so tako poučne tudi za nas, ker osvetljujejo zmogljivosti in fiziognomijo reprodukcije na Slovenskem sredi in $\mathrm{v}$ drugi polovici 18. stoletja ter $\mathrm{s}$ tem pomenijo prispevek $\mathrm{k}$ boljšemu poznavanju takratne tradicije, vzorov in glasbenega okusa, ki je bil navzoč ob nastajanju istega ali podobnega na naših tleh.

\section{SUMMARY}

The article deals with four compositions, a Parthia and three Concertos by Johann Adam Scheibl, who is considered by Austrian musicology to be one of the most important Austrian composers from the time of Maria Theresa. The compositions mentioned are preserved in manuscript only in the archives of the Ptuj Reference Library. They are characteristic and interesting as an enrichment to the stylistic picture of musical performance and creation on Slovene territory in the second half of the $18^{\text {th }}$ century, as it is justifiably supposed that they once belonged to a musical collection in one of the castles in the north-east of Slovenia. Basically, all four compositions are typically set for a trio: two soloist stringed instruments plus harpsichord. The latter plays a continuo role in places, but elsewhere its part is completely fixed, which indicates that the compostions, in general of a somewhat gallant character, belong to the transitional period between Baroque and Classicism. This is evident from the reconstructed scores: in their melodics, rhythm, harmony and form.

${ }^{34}$ Schenk E., Die Ausseritalienische Triosonate, Köln 1970, 21.

35 Graf W., ib., 100.

36 Newmann W. S., The Sonata in the Classic Era, Chapel Hill 1963, 317. 